\title{
THE IMPLICATIONS OF THE ARMY'S AUDIOMETRIC SCREENING PROGRAMME PART 1-ACOUSTIC TRAUMA AMONGST SERVING INFANTRY PERSONNEL
}

\author{
LT COL D H COOMBE, MB, MSc, DTM\&H, RAMC \\ Royal Army Medical College, Millbank
}

SUMMARY: An audiometric survey of a random sample of two hundred serving Infantrymen showed that 28 per cent of the sample had an unrecognized or unadmitted hearing loss of greater than $30 \mathrm{~dB}$ at $3-6 \mathrm{kHz}$. This indicates an unchanged prevalence of acoustic trauma amongst serving Infantrymen over the last ten years despite the availability of hearing protection for all personnel.

In addition, 10 per cent of the sample were confirmed as having hearing losses which would require their hearing to be classified as $\mathrm{H4}$ or worse, thus necessitating an assessment by a consultant in orthorhinolaryngology (ORL). Two per cent would be classified as $\mathrm{H8}$ and medically discharged under current regulations.

It is concluded that the military audiometric screening programme is likely to have major implications for the Army, the Army Medical Services, and for future Army hearing conservation strategy.

\section{Introduction}

All three services have problems in protecting the hearing of their personnel from hazardous continuous noise caused by industrial machinery, the engines of ships and aircraft, and the engines and tracks of armoured fighting vehicles.

The Army, perhaps most of the three services, also has the problem of impulse noise from military weapons, particularly from high velocity small arms such as the $7.62 \mathrm{~mm}$ self-loading rifle and general purpose machine gun, and from the larger anti-tank and artillery weapons.

It has been known for some years that the infantry, in particular, suffer from acoustic trauma caused by weapon noise. Livesey ${ }^{1}$ and Brasher $^{2}$ have shown that 30 per cent of a sample of serving Infantrymen and 30 per cent of a mixed group of serving teeth arm personnel respectively were suffering from unrecognized acoustic trauma (a hearing loss of greater than $30 \mathrm{~dB}$ in the $3-6 \mathrm{kHz}$ frequency range which could reasonably be attributed to weapon noise).

The three Services have all had separate hearing conservation programmes in operation for some years. The detail of the programmes has varied between the Services but in general they have been made up of the following parts:

a. Detection, measurement and evaluation of noise hazard.

b. Reduction of noise hazard at source and avoidance of new sources.

c. Provision of hearing protection for those exposed to noise hazard. DCI (Army) 19 of 1966 authorised the issue of ear plugs to all ranks in the Army. 
d. Screening of the hearing acuity of new entrants and regular monitoring of the hearing acuity of those exposed to noise hazard.

e. Health education regarding noise hazard.

Until recently the Army's only method of screening hearing acuity, outside of hospital ORL departments, has been the forced whisper test. The use of selfrecording or manual audiometers in an audiometric screening programme has been the subject of much controversy over the years. The recent discussion document "Audiometry in Industry" was circulated by the Health and Safety Executive to obtain comment on their proposed guidelines for an audiometric screening programme in industry. A definitive set of guidelines, based on the amended discussion document, is expected to be published later this year.

However, the Royal $\mathrm{Navy}^{3}$ and Royal Air Force ${ }^{4}$ have carried out audiometric monitoring of some of their personnel at risk for several years. The Royal Navy extended this recently to include audiometric screening of new entrants using manual audiometry at their Careers Offices. In addition, both the Royal Navy and Royal Air Force carry out base-line audiometry on new recruits at their recruit training establishments.

The Army introduced an audiometric screening programme in October 1979. Screening of recruits to obtain a base-line audiogram is being carried out using self-recording audiometers during their initial medical examination at recruit training establishments.

Regular monitoring of the hearing acuity of serving soldiers is then to be carried out using manual audiometers. This will be annually for personnel at high risk, and at the periodic medical examination for all other personnel.

The instructions for the administration of the programme, including the definition of high risk employments, has been notified to units in Army General and Administrative Instructions. The medical aspects of the programme have been published in Medical Administrative and Technical Instructions.

However, no assessment of the present levels of hearing acuity in serving soldiers has been carried out since 1969 and the present study was set up to provide up to date information on this, and to enable the implications of the planned programme to be clarified.

\section{Methods}

The sample was randomly selected from the Infantry Demonstration Battalion at Warminster. This composite unit is made up of personnel drawn from all fortytwo battalions of Infantry. It is as representative of total infantry manpower as can be obtained at any single location.

The two hundred infantrymen were selected from the battalion nominal roll using random number tables. Thirty of those originally selected had to be substituted because of non-availability, acute middle or external ear disease, or inability to grasp what was required of them. The substitutes were found by selecting the nexit name on the battalion nominal roll with the same rank, age and length of service as the original selection.

The survey was carried out using Tracor Rudmose ARJ-4C self-recording 
audiometers. All subjects were interviewed prior to carrying out their audiograms, and a questionnaire was completed which recorded information such as the subject's date of birth, recent weapon noise exposure, recognition and management of hearing loss, and the results of the analysis of the audiograms recorded in the survey.

Anonymity was preserved in the survey by the allocation of a survey serial number to each subject. The subjects were also assured that no administrative action would be taken at this stage whatever the audiometric findings were in the survey. However, if a remediable hearing problem was discovered, the individual was referred to the battalion's medical officer for treatment or an appointment to see an ORL consultant.

All questionnaires were applied at the preliminary interview by the author, who also instructed each subject in the procedure for carrying out the audiograms and supervised the recording. This enabled observer variation to be reduced to a minimum.

Pulsed tones were used throughout the survey, the audiometer presenting pulses at 2.5 pulses per second with an attenuation rate of $5 \mathrm{~dB}$ per second. This configuration was recommended by $\mathrm{McC}$ Commons and Hodge ${ }^{5}$ as being the optimum for this kind of audiometry. The machine presented the tones in ascending frequency order from $0.5 \mathrm{kHz}$ to $8 \mathrm{kHz}$ completing the left ear first and then the right ear.

On completion of the hearing test each audiogram card was stapled to the subject's questionnaire sheet. Audiometric analysis was undertaken at the Army Personnel Research Establishment (APRE), Farnborough by the author after completion of the survey and the results entered on the questionnaire sheet. The precoded data was then transferred to punched cards and disc files were created using the Royal Aircraft Establishment link to a CDC 6600 computer at the SIA Computer Bureau in Central London. Descriptive analysis and cross-tabulation of the variables were performed using the SPSS package. ${ }^{6}$

Because the survey judged hearing levels by a single audiogram recorded under less than ideal conditions, audiometric follow-up of all subjects who appeared to have a hearing classification of $\mathrm{H} 4$ or worse ("positives") was carried out at the ORL department of the Cambridge Military Hospital, Aldershot. After comparison of the survey and follow-up findings, hearing levels were confirmed or revised, and the results were tabulated.

\section{Results}

The audiograms were analysed in two ways. Firstly by Pulheems $\mathrm{H}$ classification and secondly, by hearing loss in the 3,4 or $6 \mathrm{kHz}$ frequencies. The results of the audiometric analysis using hearing levels recorded in the survey to allot PULHEEMS $\mathrm{H}$ quality gradings, together with the results of the audiometric follow-up at the Cambridge Military Hospital are shown at Table I.

The 49 subjects ( 24.5 per cent of the sample) who were found to be $\mathrm{H} 4$ or worse in the survey were reduced to 20 (10 per cent of the sample) after follow-up. 
Table I

Hearing classification of 200 serving Infantrymen after the audiometric survey and after follow-up at a Military hospital

\begin{tabular}{|c|c|c|}
\hline Classification & After survey & After follow-up \\
\hline $\begin{array}{r}\mathrm{H}_{1} \\
2 \\
3\end{array}$ & $\begin{aligned} 113 & (56.5 \text { per cent }) \\
17 & \begin{array}{l}(8.5 \text { per cent }) \\
21\end{array} \\
21 & (10.5 \text { per cent })\end{aligned}$ & $\begin{array}{r}139 \text { ( } 69.5 \text { per cent }) \\
19(9.5 \text { per cent }) 90 \text { per cent } \\
22(11.0 \text { per cent })\end{array}$ \\
\hline $\begin{array}{r}H 4 \\
5 \\
6 \\
8\end{array}$ & $\begin{aligned} 28 & (14.0 \text { per cent }) \\
6 & (3.0 \text { per cent }) \\
7 & (3.5 \text { per cent }) \\
8 & (4.5 \text { per cent } \\
8 & (4.0 \text { per cent })\end{aligned}$ & 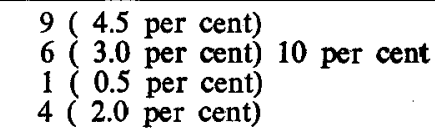 \\
\hline
\end{tabular}

Similarly, the number of subjects found in the survey to be H8 was reduced to four (two per cent of the sample) after follow-up.

The results of the audiometric analysis of the survey audiograms using the audiometric groups described by Livesey ${ }^{1}$ in his survey to grade hearing loss at 3, 4 or $6 \mathrm{kHz}$, together with the results of the audiometric follow-up are shown at Table $\Pi$.

Table II

Audiometric grouping of $\mathbf{2 0 0}$ serving Infantrymen after the audiometric survey and after follow-up at a Military hospital.

\begin{tabular}{|c|c|c|c|c|}
\hline Group & $\begin{array}{r}\text { Hearing loss a } \\
3,4 \text { or } 6 \mathrm{kHz}\end{array}$ & & After survey & After follow-up \\
\hline $\mathbf{I}$ & $0-30 \mathrm{~dB}$ & $104(52.0$ & per cent) & 133 (66.5 per cent) \\
\hline III & $\begin{array}{l}31-50 \mathrm{~dB} \\
51-70 \mathrm{~dB} \\
70+\quad \mathrm{dB}\end{array}$ & $\begin{array}{l}49(24.5 \\
33(16.5 \\
14(7.0\end{array}$ & $\begin{array}{l}\text { per cent) } \\
\text { per cent) } 48 \text { per cent } \\
\text { per cent) }\end{array}$ & 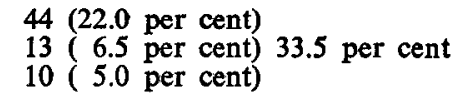 \\
\hline
\end{tabular}

The 96 subjects (48 per cent of the sample) who were found to have a hearing loss of greater than $30 \mathrm{~dB}$ at the higher frequencies in the survey were reduced to 67 (35.5 per cent) at follow-up. Eleven (5.5 per cent) of these had recognised their hearing impairment, leaving 56 (28 per cent) with an unrecognised or unadmitted hearing loss. Ten subjects (five per cent of the sample) had a hearing loss of greater than $70 \mathrm{~dB}$ confirmed at the follow-up.

\section{Discussion}

The results of both analyses of the audiometric data indicate that many false "positives", as well as all the true "positives", will be identified by a self-recorded survey of this sort using a single audiogram to determine hearing levels.

The main reasons for the upgrading of the soldier's hearing classification at follow-up were resolution of conductive deafness following previous upper respiratory infection, often associated with Eustachian catarrh, and loss of concentration during the audiometry by a number of subjects which had not been identified during the audiometric examination at Warminster.

To reduce the unnecessarily heavy workload that may fall on military ENT departments, it is essential that each medical centre carrying out audiometry 
employs a combination of careful clinioal examination and repeat audiograms to authenticate hearing losses before referral for an ORL opinion.

Even so, it would appear that up to 4,000 serving Infantry officers and soldiers (10 per cent of the Infantry strength of around 40,000) may need to be referred for an ORL specialist opinion in the first four years of the screening programme. During that period all serving personnel should have had at least one audiometric examination.

Walden and his colleagues ${ }^{7}$ in the United States have shown that the prevalence of hearing loss was much the same between armour, artillery and infantry personnel in the United States Army. It would not be unreasonable therefore to predict that a further 4,000 serving officers and soldiers from the other teeth arms (strength approximately also 40,000) will require an ORL opinion in the first four years of the programme.

A much lower prevalence of hearing loss is likely to be found amongst personnel in the supporting services, but it would be realistic to expect a further 2,000 personnel (from a strength of approximately 60,000 ) to have similar hearing losses. This would make a total of up to 10,000 serving personnel from all Arms and services who will require an ORL opinion in the first four years of the programme to assess their hearing classification and future employability in the Army.

By a similar argument up to 2,000 serving officers and soldiers could be found to be H8 and medically discharged under current regulations. Many of the officers are of field rank and above, and many of the soldiers are senior warrant officers and NCOs. This would be a loss of expertise and trained manpower that the Army could ill-afford.

A comparison between the 28 per cent prevalence of acoustic trauma in serving Infantrymen found in the present survey, and the 30 per cent prevalence found in Livesey's and Brasher's survey shows that there has been little change in the amount of unrecognised acoustic trauma amongst serving Infantrymen in the last ten years, despite the availability of adequate hearing protection for every officer and soldier. There is still a lack of awareness of the dangers of weapon noise to hearing and a certain amount of resistance to the wearing of hearing protection at all levels in the Army that must be overcome by health education and publicity if the hearing conservation programme is to be a success.

It is disturbing to find that 5 per cent of the subjects in the survey had a hearing loss greater than $70 \mathrm{~dB}$ at $3-6 \mathrm{kHz}$. As Brasher points out in his 1969 survey report, many of the warning sounds essential to an Infantryman's survival during operations, such as snapping twigs, rustle of leaves, and footsteps on gravel have significant high frequency components. This would make it very difficult for these personnel to identify and locate the warning sounds, and would make them a liability when on patrol or guard duty, particularly on internal security operations or in a conflict in North-West Europe.

One of the outcomes of the survey, and the manning implications that it raises, has been the agreement by a tri-service working party on new audio-metrically-based hearing standards. These have been adopted by the Army at the commencement of the audiometric screening programme. The new system, which supersedes that in $\mathrm{JSP} 346^{8}$, includes recording of hearing levels in each ear 
separately (this does away with the need for $\mathrm{H} 4, \mathrm{H} 5$ and $\mathrm{H6}$ ), a new wider-based $\mathrm{H} 3$ standard which will give ENT specialists greater flexibility in the grading of personnel with hearing impairment, and a new standard which will provide a holding grade to cover those personnel with aided hearing and those whose hearing disability is likely to improve.

Hearing grades are to be allocated based on the sum of the hearing losses in three low frequencies $(0.5,1$ and $2 \mathrm{kHz})$ and three high frequencies $(3,4$ and $6 \mathrm{kHz}$ ). These losses must not exceed a set limit for each grade.

The system will increase the number of pensonnel retained in the services with a hearing impairment, and will throw the onus onto ORL specialists to make careful recommendations on the future employment of these personnel and on to units to carry out the recommendations. Also, more account will be taken of noise induced hearing loss in the assessment of an individual's hearing classification.

However, this is only one of the problems highlighted by the survey and there are other implications in the survey findings which concern the Army, the Army Medical Services and future hearing conservation strategy.

\section{Implications}

The first and most obvious implication is the need for an immediate expansion of health education on the dangers of exposure to hazardous noise and the need to wear hearing protection. It should become a part of all military training programmes and be included in training objectives.

The Ministry of Defence should issue instructions reminding all weapon training instructors and range staff of their responsibility in enforcing the wearing of hearing protection by all personnel while live firing is taking place. A clear policy statement should be made on the wearing of hearing protection in military transport, particularly by passengers in tracked armoured vehicles and helicopters.

There is a need to develop a more acceptable form of hearing protection that will enable the wearing of the protection to be more easily checked. Ideally the device should not need to be fitted by a medical officer or other person.

Units must ensure that personnel with hearing impairment requiring an ORL specialist opinion attend for their appointments. Recommendations made by ORL specialists must be acted on to protect from further damage the hearing of those already showing hearing impairment. Arrangements must be made for those personnel whose hearing is severely impaired to be medically discharged and they must not be exposed to further weapon noise while awaiting the medical board.

In the Army Medical Services, sufficient technicians must be trained in audiology ito cover the extra workload at ORL departments that will occur as a result of the screening programme. There will also be a need to train an adequate number of technicians for employment at the medical centres carrying out audiometry. At present, all Medical Assistants Class I are being given itraining in basic audiometry, but to cover leave, sickness and postings this may have to be expanded to Medical Assistant Class 2 personnel as well. It is at these centres that a system of clinical appraisal and repeat audiometry must he organized to check the authen- 
ticity of apparent hearing losses shown by the initial audiogram, and thus reduce the workload referred for specialist opinion to proven cases only.

\section{Conclusions}

The survey has shown that there has been little change in the prevalence of acoustic trauma amongst Infantrymen in the last ten years despite the availability of hearing protection for all ranks.

Up to 10,000 serving officers and soldiers may require an ORL opinion, and 2,000 may require medical discharge, through hearing impairment detected in the first four years of the military audiometric screening programme.

This survey concerned only serving personnel, and a similar survey of officer and soldier recruits is described separately, but it has become clear that the programme will have many implications for the Army and the Army Medical Services.

\section{Acknowledgements}

I would like to thank Brigadiers.J P Crowdy and B Livesey for their encouragement in carrying out this survey, and Lieutenant Colonel A G Harwood for his advice in the preparation of this report.

\section{REFERENCES}

1. LiveSEY, B (1965). Acoustic trauma as an occupational hazard in Infantrymen. Journal of the Royal Army Medical Corps 111, 188-193.

2. Brasher, P F (1969). Modern weapons and the human ear. Journal of the Royal Army Medical Corps 115, 163-171.

3. WRIGHT, D S Surgeon Commander (1979). Personal communication.

4. KING, P F, Air Commodore (1978). Hearing conservation in the Royal Air Force. Journal of the Royal Society of Medicine 71, 562-573.

5. McCommons, R B and Hodge, D C (1969). Comparison of continuous and pulsed tones for determining Bekesy threshold measurements. Journal of the Acoustical Society of America 45, 1499-1503.

6. NIE, N $\mathrm{H}$ et al, SPSS. Statistical Packagel for the Social Sciences. (version 7), 2nd ed. MoGraw Hill.

7. WALDEN, B $\mathrm{E}$ et al (1975). The prevalence of hearing loss within selected US Army Branches. Walter Reed Army Medical Center Audiology and Speech Department Report 403556. Washington DC.

8. Joint Service Publication (JSP) 346. A Joint Service System of Medical Classification (1976). Paragraphs 0209 and 0211. 